\title{
RELATIONSHIP BETWEEN POWDER COMPOSITION AND SINGLE SCREW EXTRUSION FOR MANUFACTURING RELIABLE RANDOM CERAMIC PACKED BED ACCORDING STATISTICAL APPROACH
}

\author{
${ }^{\#}$ AMIN SALEM \\ Mineral Processing Research Center, Chemical Engineering Department, Sahand University of Technology, Tabriz, Iran \\ Center of Excellence for Color Science and Technology, Tehran, Iran \\ "E-mail: salem@sut.ac.ir
}

Submitted October 24, 2015; accepted January 20, 2016

\begin{abstract}
Keywords: Random ceramic bed, Reliability, Compressive strength, Failure probability, Microstructure
The present investigation provides a detailed relationship between the powder composition and reliability of random ceramic beds. This evaluation is important due to standing in the liquid-gas contactors as well as predicting lifetime. It is still unclear whether the normal distribution is the most suitable function for estimation of failure. By developing the application of ceramic beds in the chemical plants, a special attention has been paid in screening strength distributions. To achieve this goal, an experimental-theoretical study was presented on compressive strength distribution. The powder compositions were prepared according to the statistical response surface methodology and then were formed by a single screw extrusion as Raschig rings. The compressive strength of specimens was measured to evaluate the strength data sets by normal and Weibull distributions. The results were analyzed by the Akaike information criterion and the Anderson-Darling test. The accuracy of distributions in prediction fracture was discussed.
\end{abstract}

\section{INTRODUCTION}

Commercially, many random inorganic beds are available for chemical engineering process such as adsorption [1-3], distillation, humidification and absorption $[4,5]$. Despite the progress in manufacturing different kinds of beds in the last decades, the brittle nature of ceramics has still made the limited lifetime [6]. The limitations of metal beds due to corrosion in acidic environments have triggered the development of ceramic materials. The fracture of ceramics in service takes place with little or no plastic deformation when cracks propagate under applied compressive stress [7]. If the stress intensity reaches a critical level at the crack tip, fracture occurs immediately [8]. Ceramic bodies indicate considerable variation in strength, due to their extreme sensitivity to the presence of defects with different sizes like pores [9]. The fracture of body starts from critical flaws and always propagates from the largest flaw, favorably oriented in the tensile stress direction $[10,11]$. The defect size, shape, distribution and orientation statistically affect the compressive strength.

Raschig ring is a hallow cylinder which is the simplest shape of random beds and frequently is used in separation processes [6]. Lessing ring and others with internal partitions are less applied in comparison to Raschig ring in the liquid-gas contactors. The saddle, Berl, Intalox and Pall ring are the other types of random packings. Unfortunately, the breakage of bed increases the process problems such as pressure drop. The ceramic bed compositions at least consist of three components that play the fundamental roles in processing and performance of chemical units. Kaolin, for plasticity [9, 12], nepheline syenite $[13,14]$ or talc [15] with limited content as fluxing agents and alumina and zirconium silicate [16] as fillers were applied. After suitable processing, these formulations should lead to a matrix with high strength and appropriate chemical resistance $[7,16]$. The typical microstructure of ceramic body consists of a glassy matrix that contains mullite and/or partially undissolved quartz particles. Mullite, $3 \mathrm{Al}_{2} \mathrm{O}_{3} \cdot 2 \mathrm{SiO}_{2}$, is the principal crystalline phase formed during the sintering process. The shape and content of this crystal influence the mechanical properties $[17,18]$. According to glass/crystalline ratio and sintering temperature, $1200-1250^{\circ} \mathrm{C}$, this type of ceramics can be categorized into porcelain stoneware group.

In order to achieve the reliable methodology in the fabrication of ceramic beds, the strength data should be analyzed by statistical approaches, because the probability of failure potentially depends on a dangerous crack, greater than a characteristic critical flaw. Also, the fracture depends on volume of material under the stress because the larger volume increases the probability of critical flaw content. One of the commonly used methods for the evaluation of strength distribution and structural reliability of ceramic materials is the Weibull statistical theory, which describes the strength of a brittle material based on the failure probability [11]. The stressed volume is evaluated by a normalizing parameter, corresponding 
to the strength in which $63.2 \%$ of the samples are failed and the Weibull modulus which indicates the nature and dispersion of cracks. Higher Weibull modulus is related to materials with homogenously distribution of cracks in the narrow strength range whilst the lower values indicate heterogeneously distribution of flaws. The slow and stable crack growth is observed in ceramic materials when they are subjected to stress below the critical value, especially in the presence of chemical agents. The strength degradation over time and reducing the lifetime of material are result of crack growth. If chemical agents are presented at crack tip under stress, the chemical reaction between the agent and ceramic material may be lead to break of bonds. Consequently, the crack grows slowly until reaching the critical size for fracture. Literatures report the Weibull modulus values for ceramic Raschig rings between 3 and 15, [13-16]. This introduces the necessity to investigate the reliability of ceramic beds, which are normally polycrystalline solids, existing in abundant glassy phase. Generally, the main challenge in the reliable design of ceramic beds is the exact estimation of failure probability under prescribed load. Due to the scatter of position, length and orientation of critical cracks, the strength of ceramics vary unpredictably from one composition to another composition, even if identical specimens are tested. Thus, in the design of engineering ceramics, a probabilistic technique is recommended.

In this study, the author intends to present a detailed microstructural characterization on different ceramic compositions fabricated for liquid-gas contactors. These observations show that the well understanding fracture behavior and its relation to microstructure are important from capability of standing in aggressive environment. It also can be helpful in developing new materials with sufficient mechanical properties. In order to achieve this goal, ten strength data sets of ceramic beds in the form of Raschig rings are fitted by normal and Weibull distributions. Based on the minimum information criterion and the Anderson-Darling methods, the most suitable distribution is determined and the deviations are discussed in details.

\section{MATERIALS AND METHODS}

\section{Raw materials}

Kaolin, nepheline syenite and talc collected from a ceramic industry of Iran were selected as raw materials. These materials were procured in ground form with grain size of $63 \mathrm{~mm}$, maximum. The chemical analysis was performed by X-ray fluorescence technique (Model S4 Explorer 7KP103, Brucker, Karlsruhe, Germany). Mineralogical analyses were carried out with an X-ray powder diffractometer $(\mathrm{Cu}-\mathrm{Ka}$, Ni-filtered radiation, (XRD; Model D8-Advance, Brucker, Karlsruhe, Germany).
Experimental design

The conventional techniques for optimization involve changing one variable at a time and keeping the others in constant level. The interaction effects of variables cannot be considered in these methods. However, the response surface methodology is a useful technique for studying the effect of several parameters by changing the variables, simultaneously. Also, the optimization of mechanical characteristics by the classical methods is extremely expensive when more than two variables are evaluated. In order to overcome this problem, the response surface methodology was selected to optimize the mechanical properties. The main use of mixture design in this study is to reliably guarantee the dependency between composition and the outcome of experiments, with the minimal number of experiments. In the experimental design, the following effects were considered. (i) The effect of kaolin on mechanical properties. (ii) The binary mixing of materials which provides the second order interactions. (iii) The experimenters which represent the ternary influence of materials. The response surface algorithm, which is considered in this investigation for mixing of raw materials, is based on statistical and mathematical technique for determining optimum composition. In this experiment approach, the total amount of materials is kept constant and measured properties can be evaluated as a function of component fractions. The best composition can be determined by using the composition-property in a triaxial diagram. A polynomial equation, which describes the property, can be correlated as a function of material fractions, $x_{i}$. In a system with $n$ components, there are $n-1$ independent compositions. The polynomial function, $f\left(x_{i}, x_{j}, x_{k}\right)$, can be expressed by the following equation [19]:

$$
\begin{aligned}
& f\left(x_{i}, x_{j}, x_{k}\right)=\beta_{0}+\sum_{i=1} \beta_{i} x_{i}+\sum \sum_{i<j} \beta_{i j} x_{i} x_{j}+ \\
& +\sum \sum_{i<j} \sum_{j<k} \beta_{i j k} x_{i} x_{j} x_{k}+\ldots
\end{aligned}
$$

where $b$ is the constant of equation. This equation should be evaluated over $M>n$ number of points (in this study, $M$ was considered to be 10). Figure 1 shows the location of points in the mixture space and the component fractions are given in Table 1. The maximum amount of kaolin was considered to be $100.00 \mathrm{wt} . \%$ and at the most 5.00 wt. \% of nepheline syenite and/or talc was applied. The compositions were denoted by capital letters, A-J, as reported in Figure 1.

The triangle design with axial and central points is especially useful for ternary studies. In order to evaluate the effect of maximum content of materials on mechanical properties, the points at the vertexes of triangle were considered. The points centered on each leg of triangle are related to the binary mixtures. The point in the center of triangle represents a ternary mixture 
of materials. The interior points between the centroid and vertexes represent the axial mixes. These mixtures contain a $2 / 3$ portion of one and $1 / 6$ portions of the other materials. The individual proportions cover from zero to $5.00 \mathrm{wt} \%$ for fluxing agent content, from base to vertex, in each of three axes. It is possible to introduce constraints on individual positions and increase the number of experimental points. In this case

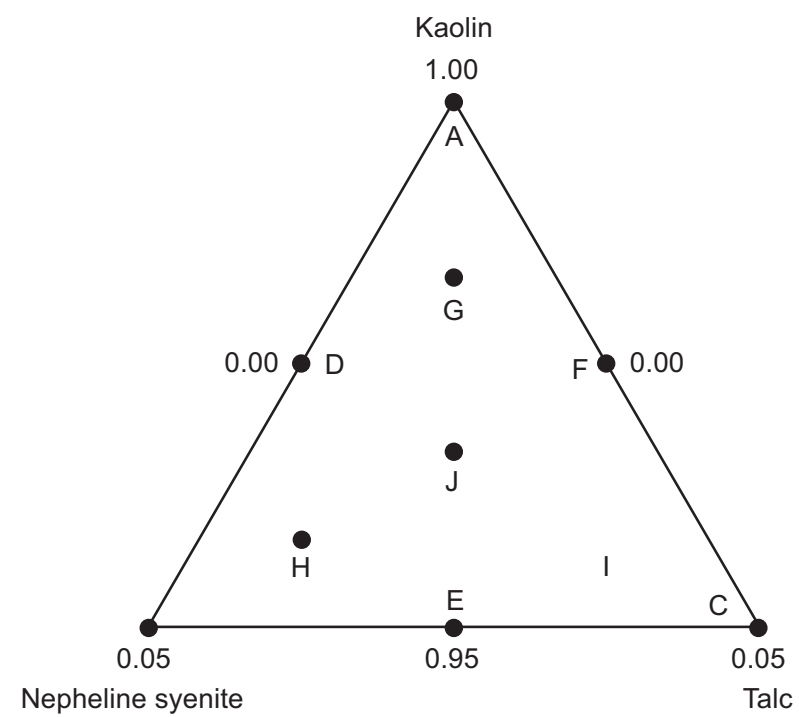

Figure 1. Experimental design and the location of selected points in the mixture space.

Table 1. Proportions (wt. \%) of raw materials in ceramic compositions.

\begin{tabular}{cccc}
\hline Composition & Kaolin & Nepheline syenite & Talc \\
\hline A & 100.00 & 0.00 & 0.00 \\
B & 95.00 & 5.00 & 0.00 \\
C & 95.00 & 0.00 & 5.00 \\
D & 97.50 & 2.50 & 0.00 \\
E & 95.00 & 2.50 & 2.50 \\
F & 97.50 & 0.00 & 2.50 \\
G & 98.34 & 0.83 & 0.83 \\
H & 95.84 & 3.33 & 0.83 \\
I & 95.84 & 0.83 & 3.33 \\
J & 96.66 & 1.67 & 1.67 \\
\hline
\end{tabular}

the experimental design will be complicated and it is out of the article scope. The Minitab 15 software package (Iran) can set up the individual constrains on the triangle design. The chemical analyses of the compositions are listed in Table 2. The clay is constituted by kaolinite, illite and pyrophilite. Albite, orthoclase and oligoclase are the main crystalline phases of nepheline syenite. The frequently phase, existing in the second fluxing material is talc. The content of other phases are negligible.

\section{Ceramic Raschig ring preparation}

Various batches were wetted with 30.0 wt. \%, based dry weight of powder, of de-ionized water and mixed for $2 \mathrm{~h}$. The samples were maintained in closed plastic bags for $48 \mathrm{~h}$ to homogenize the paste humidity and then de-aired by a laboratory pug-mill. A single screw extruder, prototype, were used in forming green tubes and the shaped samples were dried at $90^{\circ} \mathrm{C}$ during $48 \mathrm{~h}$. The obtained specimens were cut in the shape of Raschig ring (Figure 2), with the same external diameter



Figure 2. Liquid-gas contactor and schematic of manufactured ceramic Raschig rings.

Table 2. Chemical analyses (wt. \%) of selected compositions.

\begin{tabular}{lrrrrrrrrrr}
\hline Oxide & \multicolumn{1}{c}{$\mathrm{A}$} & \multicolumn{1}{c}{$\mathrm{B}$} & \multicolumn{1}{c}{$\mathrm{C}$} & \multicolumn{1}{c}{$\mathrm{D}$} & \multicolumn{1}{c}{$\mathrm{E}$} & \multicolumn{1}{c}{$\mathrm{F}$} & $\mathrm{G}$ & $\mathrm{H}$ & $\mathrm{I}$ & $\mathrm{J}$ \\
\hline $\mathrm{SiO}_{2}$ & 59.21 & 58.98 & 58.89 & 59.10 & 58.94 & 59.05 & 59.12 & 59.01 & 58.96 & 59.03 \\
$\mathrm{Al}_{2} \mathrm{O}_{3}$ & 28.59 & 28.21 & 27.22 & 28.40 & 27.72 & 27.90 & 28.30 & 28.11 & 27.61 & 28.01 \\
$\mathrm{~K}_{2} \mathrm{O}$ & 4.59 & 4.73 & 4.36 & 4.66 & 4.55 & 4.48 & 4.58 & 4.65 & 4.46 & 4.56 \\
$\mathrm{Na}_{2} \mathrm{O}$ & 0.20 & 0.70 & 0.20 & 0.45 & 0.45 & 0.20 & 0.29 & 0.53 & 0.28 & 0.37 \\
$\mathrm{CaO}$ & 0.51 & 0.52 & 0.57 & 0.52 & 0.55 & 0.54 & 0.52 & 0.53 & 0.55 & 0.53 \\
$\mathrm{MgO}$ & 0.15 & 0.14 & 1.89 & 0.15 & 1.02 & 1.02 & 0.44 & 0.44 & 1.31 & 0.73 \\
$\mathrm{Fe}_{2} \mathrm{O}_{3}$ & 0.36 & 0.36 & 0.44 & 0.36 & 0.40 & 0.40 & 0.37 & 0.37 & 0.41 & 0.39 \\
$\mathrm{TiO}_{2}$ & 0.26 & 0.24 & 0.25 & 0.25 & 0.24 & 0.25 & 0.25 & 0.25 & 0.25 & 0.25 \\
L.O.I* & 6.13 & 6.10 & 6.17 & 6.11 & 6.14 & 6.15 & 6.13 & 6.12 & 6.15 & 6.13 \\
\hline
\end{tabular}

* Loss on ignition 
and length, $25 \mathrm{~mm}$. The test specimens were heated in a laboratory electrical kiln (Model EX.1500-6L, Exciton, Iran) to $573^{\circ} \mathrm{C}$ at heating rate of $5.0^{\circ} \mathrm{C} \cdot \mathrm{min}^{-1}$ and held in this temperature for $1 \mathrm{~h}$ to complete the quartz inversion. Finally, the temperature of the furnace was increased at a rate of $10.0^{\circ} \mathrm{C} \mathrm{min}^{-1}$ to reach $1190^{\circ} \mathrm{C}$ and held at this peak temperature for $2 \mathrm{~h}$ in the air atmosphere.

\section{Raschig ring characterizations}

In order to characterize the fired samples, the total porosity was measured by Archimedes technique $[20,21]$. The diameter and length of the samples were determined using a micrometer. The diametrical compression strength was measured by the universal test machine (Model DY-26, Adamel Lhomargy, Roissy en Brie, France). The Raschig rings were loaded using the steel compression plates at a head speed of $1.0 \mathrm{~mm} \cdot \mathrm{min}^{-1}$. At least 20 samples were tested to measure the diametrical compression strength of Raschig rings. The microstructure of the fired specimens was studied by scanning electron microscopy (SEM, Model 440I EOL, Oxford, UK) on freshly fracture and gold coated section.

\section{Statistical theories for} ceramic bed evaluation

In reliable design of engineering ceramics, the failure probability should be considered. It is difficult and even impossible to determine a failure probability function directly by experimental tests. Therefore, the statistical techniques are frequently used for the determination probability function, indirectly. The selection a correct or best-fitting distribution for a given set of compressive strength data is an important step, especially when the probability function is sensitive to the assumed model. In presented investigation, normal and Weibull distributions are used in the prediction of failure. The normal distribution is widely applied to analyze lifetime of samples in design of ceramic devices. It is a distribution that can be taken to account in the characterization the other types of distributions. The form of normal function can be presented as [22]:

$$
P(\sigma)=\frac{1}{\alpha \sqrt{2 \pi}} \exp \left[-\frac{\left(\sigma-\sigma_{a}\right)^{2}}{2 \alpha^{2}}\right]
$$

where $P(s)$ is the failure probability of a ceramic ring due to flaws, $\sigma$ is the uniaxial applied stress, $\sigma_{a}$ and $\alpha^{2}$ are the mean and variance of compressive strength, respectively which are calculated according to following equations:

$$
\begin{gathered}
\sigma_{a}=\frac{1}{N} \sum_{i=1}^{N} \sigma_{i} \\
\alpha^{2}=\frac{1}{N} \sum_{i=1}^{N}\left(\sigma_{i}-\sigma_{a}\right)^{2}
\end{gathered}
$$

where $\sigma_{i}$ is the compressive strength of the $i^{\text {th }}$ sample and $N$ is the number of data.

The Weibull distribution for the brittle materials such as ceramics was developed as a follows [11]:

$$
P(\sigma)=1-\exp \left[-\left(\frac{\sigma_{i}}{\sigma_{0}}\right)^{m}\right]
$$

where $\sigma_{0}$ is Weibull characteristic strength corresponded to the stress at which the probability of failure is $63.2 \%$. Weibull modulus, $m$, controls the shape of curve, being larger as scattering degree of diametrical compression strength decreases. Therefore, the high value of Weibull modulus describes the reliable material. By maximizing its log-likelihood function, the two parameters in the Weibull distribution are determined [23]:

$$
\frac{\sum_{i=1}^{N}\left(\sigma_{i}\right)^{m} \ln \left(\sigma_{i}\right)}{\sum_{i=1}^{N}\left(\sigma_{i}\right)^{m}}-\frac{1}{N} \sum_{i=1}^{N} \ln \left(\sigma_{i}\right)-\frac{1}{m}=0
$$

and

$$
\sigma_{0}=\left[\frac{\sum_{i=1}^{N}\left(\sigma_{i}\right)^{m}}{N}\right]^{\frac{1}{m}}
$$

The Akaike information criterion, $A I C$, method is one of the strongest techniques for determination appropriate strength distribution, promising to obtain the confidence bounds. The AIC determines the agreement of fit for an estimated statistical model by linking the likelihood to a distance between experimental and assumed distributions [24] and is defined as:

$$
A I C=-2 \ln Y+2 k
$$

where $k$ is the number of parameters to be fitted and is considered to be 2 for Weibull distribution. $\ln Y$ is the maximized log-likelihood for a given model and can be calculated by:

$$
\ln Y=\sum_{i=1}^{N} f\left(Y_{i}\right)
$$

where $f\left(Y_{i}\right)$ is the probability density function of an estimated distribution. The AIC values can be directly compared, preferring the distribution which gives the smallest value. In typical cases, the difference in $A I C$ values (at least 1.5-2) corresponds to a reliable indication that one distribution is superior to another [24].

The Anderson-Darling test, $A D T$, is used to select the best fit for a specific population. It is one of the most powerful statistical tools for detecting departures from normality [25]. The equation for the $A D T$ of ordered data can be presented as:

where

$$
A D T^{2}=-N-S
$$

$$
S=\sum_{i=1}^{N} \frac{2 i-1}{N}\left[\ln F\left(Y_{i}\right)+\ln \left(1-F\left(Y_{N+1-i}\right)\right)\right]
$$


where $F$ is the cumulative distribution function. Normally, the $A D T$ is compared to a critical value and then it is determined whether the data confirm specified distribution. In this work, the distribution is desirable that presents the small $A D T$.

\section{RESULTS AND DISCUSSION}

\section{Mechanical behaviors}

The parameters of normal and Weibull distributions are reported for data sets in Table 3. Ceramic Raschig rings exhibit a rather wide range of mean strength. The addition of nepheline syenite to the composition causes an enhanced strength, inferred by the abundant glassy phase in samples $\mathrm{C}, \mathrm{E}$ and $\mathrm{H}$ respect to A, D and G. Talc-bearing rings are also characterized by improved compressive strength. This aspect was confirmed by the body $\mathrm{C}$ and I which show strength near to $50.0 \mathrm{MPa}$. The other talc-rich rings, $\mathrm{F}$ and $\mathrm{J}$, did not demonstrate the same effect on strength. However, the mixture prepared with 2.50 wt. $\%$ of nepheline syenite, D, indicates a lower strength in comparison to $\mathrm{F}$.

The results of variance analysis for the investigated compositions are given in Table 3. The $\alpha$-value indicates which of the studied compositions are statistically significant, based on examination of experimental data. If the $\alpha$-value is less than or equal to $1.5 \mathrm{MPa}$, the effect is considered significant. The main effect of a factor must be interpreted individually if there is no interaction with other factors. When one or more interaction effects are significant, the interacting factors must only be considered jointly. All $\alpha$-values less than or equal to 1.5 are related to rings with lower strength, $<16.0 \mathrm{MPa}$. The compositions containing lower amounts of nepheline syenite and talc, both less than 2.5 wt. \%, causes the limited variance. $\alpha$-values can be useful in comparing the strength distribution as a function of fluxing agent content. The significant change is observed with addition of fluxing agents. The product prepared with $3.33 \mathrm{wt}$. \% nepheline syenite and 0.83 wt. $\%$ talc, $\mathrm{H}$, shows the

Table 3. Parameters of normal and Weibull distributions.

\begin{tabular}{cccccc}
\hline Composition & \multicolumn{2}{c}{ Normal } & & \multicolumn{2}{c}{ Weibull } \\
\cline { 2 - 3 } \cline { 5 - 6 } & $\sigma_{a}(\mathrm{MPa})$ & $\alpha(\mathrm{MPa})$ & & $m$ & $\sigma_{0}(\mathrm{MPa})$ \\
\hline $\mathrm{A}$ & 14.6 & 1.5 & & 10.04 & 15.3 \\
$\mathrm{~B}$ & 28.6 & 9.6 & & 3.56 & 31.9 \\
$\mathrm{C}$ & 55.9 & 5.6 & & 12.82 & 58.4 \\
$\mathrm{D}$ & 11.6 & 1.6 & & 7.47 & 12.3 \\
$\mathrm{E}$ & 50.4 & 7.1 & & 8.28 & 53.4 \\
$\mathrm{~F}$ & 15.9 & 1.5 & & 10.05 & 17.2 \\
$\mathrm{G}$ & 11.1 & 1.2 & & 9.94 & 11.4 \\
$\mathrm{H}$ & 35.3 & 11.1 & & 3.62 & 39.3 \\
$\mathrm{I}$ & 49.2 & 6.5 & & 9.02 & 52.0 \\
$\mathrm{~J}$ & 13.7 & 1.3 & & 9.08 & 14.6 \\
\hline
\end{tabular}

maximum value but the minimum $\alpha$ is related to sample $\mathrm{G}$. Nepheline syenite is more efficient between the selected materials when more than 3.33 wt. $\%$ is added to composition. The increment in talc content also raises the $\alpha$-value.

Table 3 reports the Weibull parameters. Sample B indicates the lowest $m$ value among all materials and other ceramics show similar Weibull modulus, ranging from 3.6 to 12.8 . A uniform variation is observable by changing kaolin and talc content. The highest value is related to sample $\mathrm{C}$ in which $5.00 \mathrm{wt}$ \% talc is used. The inverse behavior is observed in Weibull modulus with content of nepheline syenite and this factor is very sensitive to fluxing agent composition. Therefore, for manufacturing the satisfactory ceramic bed, the evaluation of fluxing agent composition by response surface methodology is required. The $m$-values of a simplex centroid design with axial points are analyzed with emphasis on choosing and validating the correct model. A polynomial model, Equation 12, was adjusted to the experimental data and the standard non-linear regression coefficient was calculated from the experimental and estimated values. The first three terms of Equation 12 represent the linear model. The next three terms represent synergic or antagonistic binary interaction effects for the all possible pairs of components and, along with the linear terms, forms the quadratic model. The last term represents the ternary interaction effect and is usually important for systems having maximum or minimum values in the interior of triangle. This model was statistically found to be most adequate with a regression coefficient of $\mathrm{R}^{2}=98.2 \%$.

$$
\begin{aligned}
& m=10 x_{1}-375 x_{2}+340 x_{3}+ \\
& +323 x_{1} x_{2}\left(x_{1}-x_{2}\right)^{2}-356 x_{1} x_{3}\left(x_{1}-x_{3}\right)^{2}- \\
& -12918287 x_{2} x_{3}\left(x_{2}-x_{3}\right)^{2}+594 x_{1} x_{2} x_{3}
\end{aligned}
$$

Equation 12 allows rapid prediction for the entire compositions under investigation. The coefficient of talc is higher than the coefficient of nepheline syenite. On the contrary, the coefficient related to the ternary combination of raw materials is positive. It can be concluded that the mixing of kaolin, nepheline syenite and talc for manufacturing ceramic Raschig ring is efficient to achieve reliable matrix and the only use of nepheline syenite as a fluxing agent cannot play an effective role in the improvement of Weibull modulus. Regard to the characteristic strength, the samples prepared with low content of fluxing agents present the lowest value, $<15 \mathrm{MPa}$. The strength was found to decrease with content of kaolin, indicating the week bonding between the particles. The significant increase is observed in the rings prepared with maximum amounts of talc, 5.0 wt. \%. The opposite trend is observable in body containing maximum amount of nepheline syenite. Regardless sample B, when the summation of fluxing agent content is considered to be $5.00 \mathrm{wt}$. \%, 
the maximum characteristic strength is obtainable. The sufficient increment in strength is observed in samples $\mathrm{C}, \mathrm{E}$ and I. The ring prepared with $97.5 \mathrm{wt} . \%$ kaolin and 2.50 wt. \% nepheline syenite, $\mathrm{D}$, shows the minimum strength, $12.3 \mathrm{MPa}$, between ten studied compositions. The combination of nepheline syenite and talc also slightly affects the strength of ring.

The total porosity of Raschig rings are presented in Figure 3 as a function of starting material proportions. The fluxing agent type and content influence the porosity, causing a sharp change in bulk density due to diffusion of liquid phase into the open pores in high sintering temperature. By applying an appropriate combination of raw materials it is possible to control the ceramic porosity. It is evident that the low porosity is related to the ring prepared by high content of fluxing

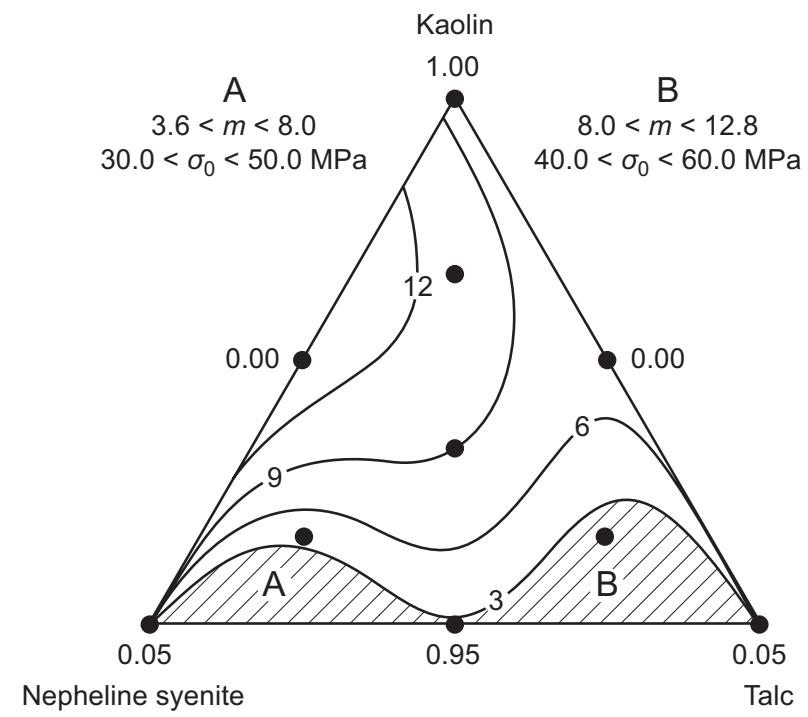

Figure 3. Total porosity of Raschig rings as a function of material proportions.

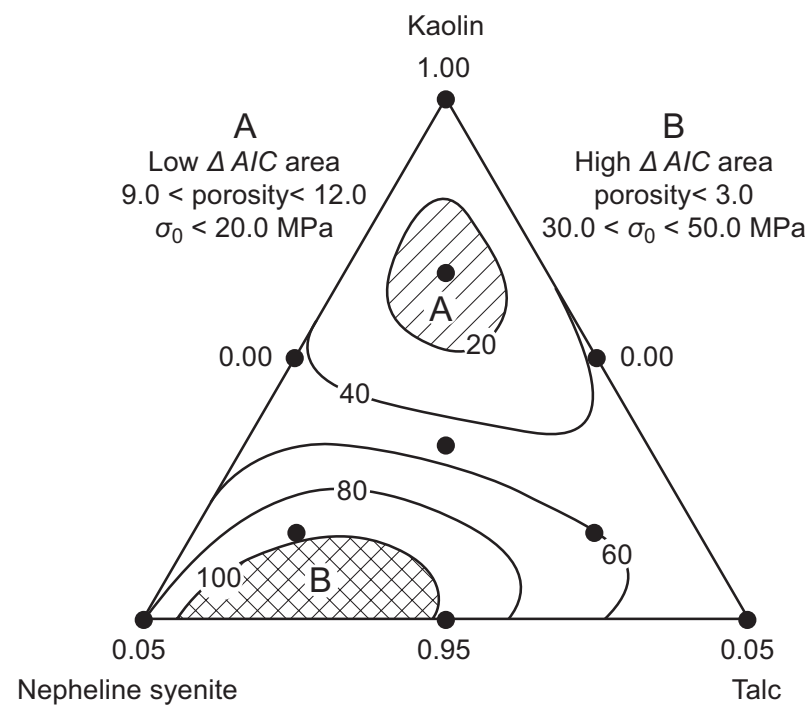

Figure 4. Variation of $\triangle A I C$ as a function of material proportions. agents and is due to densification of sample during the sintering process. The highest porosity corresponds to the composition prepared by low content of nepheline syenite and talc.

Total porosity effectively controls the Weibull modulus and characteristic strength. The strength was inversely proportional to total porosity and increases exponentially with reduce in porosity. The highest characteristic strength that corresponds to the lowest porosity, $<3.0 \%$, was found to be $58.0 \mathrm{MPa}$, sample C. Generally, in the ceramic compositions containing clays and fluxing agents, the mullite formation improves the strength [17]. The simultaneously improvement in Weibull modulus and characteristics strength is the most pronounced if the amount of talc is higher than 3.33 wt. $\%$.

\section{Statistical analyses}

In order to compare the adjustment of failure probabilities, the $A I C$ index was calculated and the results are reported in Table 4 . In the evaluation of $A I C$, the normal distribution is used as a reference and $\triangle A I C$ which is the difference between $A I C$ indexes of normal and Weibull distributions are used. $\triangle A I C>0.0$ means that the Weibull distribution fits strength data better than the normal distribution. The variation of $\triangle A I C$ is illustrated as a function of composition in Figure 4. Based on the $A I C$ indexes, when $\triangle A I C>2.0$, an optimal distribution can be identified. According to the data presented in Table 4, there is big difference between the $A I C$ values of normal and Weibull distributions. For data set $\mathrm{G}$, both of normal and Weibull distributions fit the strength data. Regardless the G composition, Weibull distribution gives the lowest $A I C$ values and is more suitable to fit those strength data. For data sets of B, $\mathrm{E}$ and $\mathrm{H}$ which contain the predominately nepheline syenite, Weibull distribution is an appropriate function for fitting the strength data and the normal distribution cannot provide the better fit. For data set of $G$, there are two different results: Weibull is the best distribution and normal function can be used with limited error.

Table 4. $A I C$ values of Raschig ring compositions calculated by normal $\left(A I C_{N}\right)$ and Weibull $\left(A I C_{W}\right)$ distributions.

\begin{tabular}{crc}
\hline Composition & $A I C_{N}$ & $A I C_{W}$ \\
\hline A & 70.8 & 40.6 \\
B & 116.9 & 37.0 \\
C & 99.4 & 37.0 \\
D & 72.1 & 34.3 \\
E & 132.7 & 40.1 \\
F & 70.6 & 31.5 \\
G & 63.8 & 37.3 \\
H & 152.0 & 43.4 \\
I & 110.9 & 38.0 \\
J & 66.4 & 36.5 \\
\hline
\end{tabular}


When the porosity of ring is less than $3.0 \%$ normal distribution fits strength data worse than Weibull function. The noticeable success of Weibull distribution in fitting the strength data of dense rings is substantiated. Figure 4 indicates that the most favorable distribution for rings containing high content of fluxing agents is Weibull distribution. Especially, for rings prepared with high amount of nepheline syenite, a high deviation is observed from the normal distribution. As illustrated in Figures 3 and 4, the deviation from normal distribution is directly related to porosity.

Based on the Anderson Darling test, the distribution which provides the smallest $A D T$ value is more suitable function for the investigated strength data. The comparison of results in Figure 5 shows that the Weibull distribution gives the best fits with all obtained data. By considering the content of raw materials in the compositions, it is possible to determine the desired area in which the normal distribution indicates the better adjustment, Figure 5a. The $A D T_{N}$ value increases as a function of nepheline syenite content in which the lower porosity is obtained. The lower value of $A D T_{N}$ is related to rings manufactured with lower content of fluxing agents. The high value of porosity is responsible for reducing $A D T_{N}$. The adjustment of normal distribution in dense rings is improved with increment in talc content. From this point of view, talc is more efficient material compared to nepheline syenite.

The change in $A D T_{W}$ of ceramic Raschig ring sets is illustrated in Figure $5 \mathrm{~b}$. The samples prepared with higher content of nepheline syenite indicate the well fit with Weibull distribution. $A D T_{W}$ gradually increases with addition in content of talc and kaolin. The $A D T_{W}$ values of samples prepared by high amount of talc are considerably lower than that for the rings containing higher content of kaolin. However, the composition containing $2.50 \mathrm{wt}$. \% nepheline syenite and $97.5 \mathrm{wt}$. \% kaolin, sample D, indicates the maximum deviation from Weibull distribution.

The combination of materials significantly affects the adjustment of distribution. The synergistic interaction is observed between the porosity and $A D T_{W}$. The deviation increases with porosity and the lower $A D T_{W}$ value is obtainable for dense rings. According to the Anderson-Darling technique, it is possible to fabricate the rings with suitable reliability which satisfies the Weibull distribution. In other word, mixing of talc and kaolin is more efficient with the best performance due to an effective increment in Weibull modulus. Though, the $A D T_{W}$ value increases directly with content of kaolin, the meaningful relationship is observable between $A D T_{W}$ value and total porosity, Figure 3.

\section{Microstructural evaluations}

The morphology of crack in sample A is presented in Figure 6. The elongated cracks with the size of $500 \mathrm{~mm}$ are dispersed in some regions of ceramic matrix. The fine pores were more homogeneously distributed in cross section of ring. These interconnected pores were presented in a wide size distribution and different morphologies.

There are two important prerequisites for the occurrence of a fracture in rings: (i) the structure fails if one single flaw becomes critical and (ii) interaction dangerous flaws. A negligible interaction between flaws is only possible if the defect density is low. Sample A is porous materials, in which the grains are covered by small pores. In Figure 6, the clusters of pores were observed around the crack. A group of pores as well as



a)

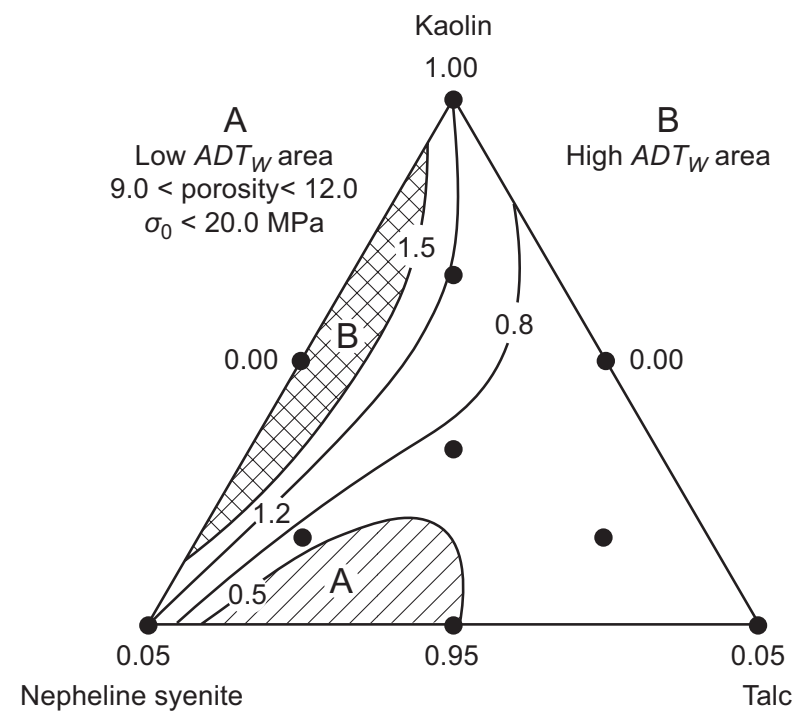

b)

Figure 5. Variations of: a) $A D T_{N}$ and b) $A D T_{W}$ as a function of material proportions. 
their interaction cannot affect the final fracture because only the largest one is postulated the weakest-link hypothesis. The defect size is a natural consequence of Weibull distribution and by checking the crack effect, it is possible to determine whether a data set obeys the Weibull distribution or not. If a pore diameter is large than the grain size, the role of pore exponentially increases respect to fracture otherwise, it has no influence on strength. Under these conditions, strength depends on the sizes of crack. The defect with large dimension in the structure of ring is responsible for the low values of characteristic strength.

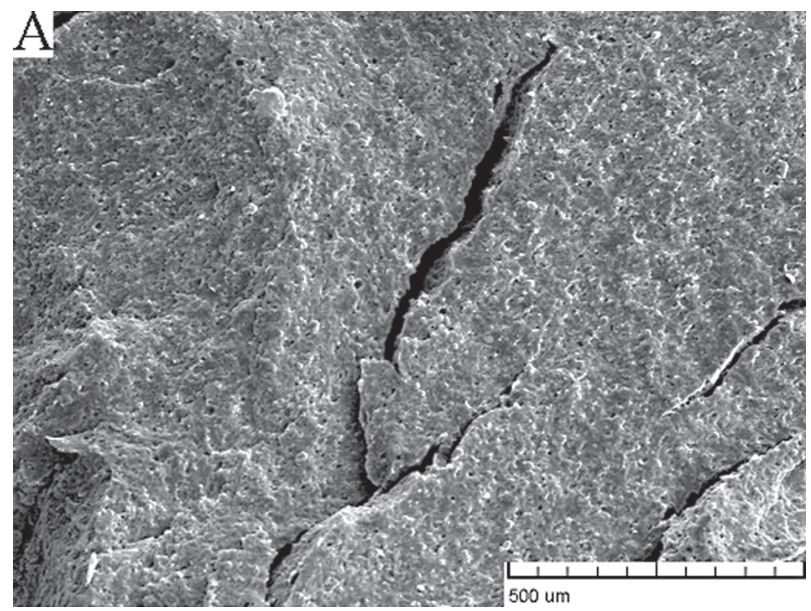

Figure 6. SEM micrograph of sample A.

The SEM micrograph of sample $B$ is shown in Figure 7. According to the microstructural observation, if $5.00 \mathrm{wt}$. \% nepheline syenite is partially replaced with kaolin, the defect dimensions decrease considerably. These changes significantly promote the characteristic strength up to $32.0 \mathrm{MPa}$. However, reduce in Weibull modulus is due to decrease in homogeneity of ceramic matrix and randomly distribution of cracks during the extrusion.

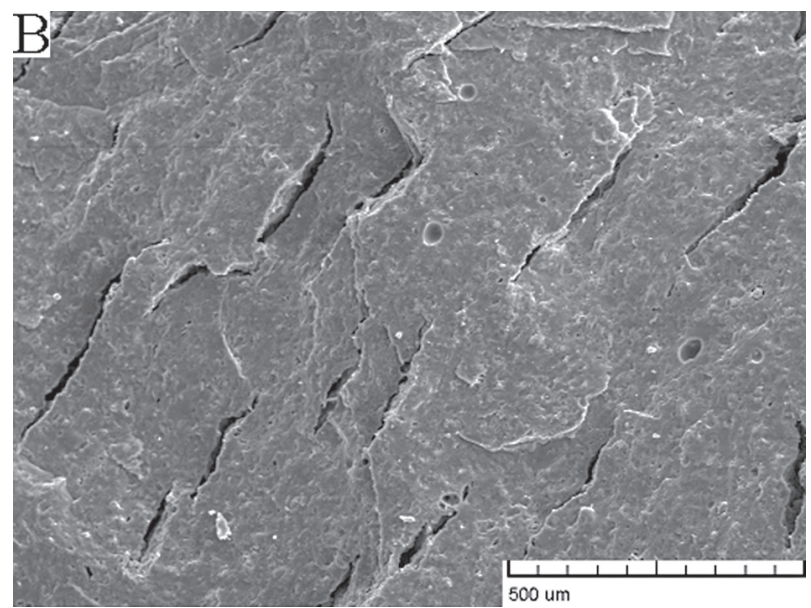

Figure 7. SEM micrograph of sample B.
Hence, it is impossible to eliminate the inherent defects in the structure of ring by addition of $5.00 \mathrm{wt}$. \% nepheline syenite. A significant difference between the morphology of pores was found in comparison to sample A. The spherical pores with small size are distributed in dense microstructure. The potential reason that causes the deviation from the normal distribution is the substantially decrease in the number of interconnected pores.

The SEM micrograph taken from sample C, Figure 8, represents some defects throughout the ceramic matrix. The limited number of defects with size less than $250 \mu \mathrm{m}$ embedded into the structure. In comparison to sample B, reduce in the number of cracks is the main reason for the increment in strength. The SEM micrograph reveals the homogenized distribution of defects that causes the improvement of Weibull modulus. In the studied cases, the amount of talc is highly important for the mechanical behavior, since talc acts as an interfacial phase that reduces the resistance to sliding of particles [26]. The fine particles of talc with a laminar structure and smooth surface provide an effective lubrication on rough surface of clay minerals therefore, the Weibull modulus of sample B is less than that for C.

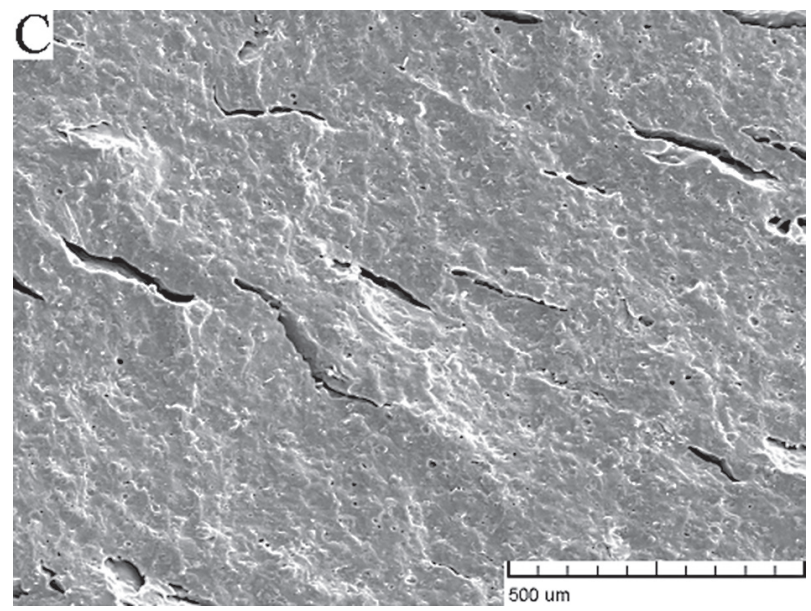

Figure 8. SEM micrograph of sample C.

The SEM images of sample E, F and I are represented in Figure 9 to evaluate the effect of talc content on microstructure. Figure 9a shows a relatively heterogeneous structure with some micro-pores with mean size of $50 \mu \mathrm{m}$ in diameter, estimated from SEM micrographs. The presence of nepheline syenite in composition makes the liquid phase formation with low viscosity as a result a dense structure was obtained due to viscous flow sintering. The microstructure of ring prepared by 2.50 wt. \% talc, sample F, is shown in Figure 9b. The pore clusters were observed around elongated cracks. The microstructure exhibits homogeneous matrix with relatively low porosity, indicating that $1190^{\circ} \mathrm{C}$ was enough to yield dense ceramic material. The large

Ceramics - Silikáty 60 (1) 48-57 (2016) 
cracks are seen to be dispersed in the body, generating some stress that results in lower characteristic strength. Figure 9c shows SEM observation on fracture surface of the ring prepared by 3.33 wt. $\%$ talc and 0.83 wt. $\%$ nepheline syenite, sample I. The existence of small cracks with irregular shape, $250 \mu \mathrm{m}$, homogenously distributed in a ceramic matrix affects Weibull modulus. The

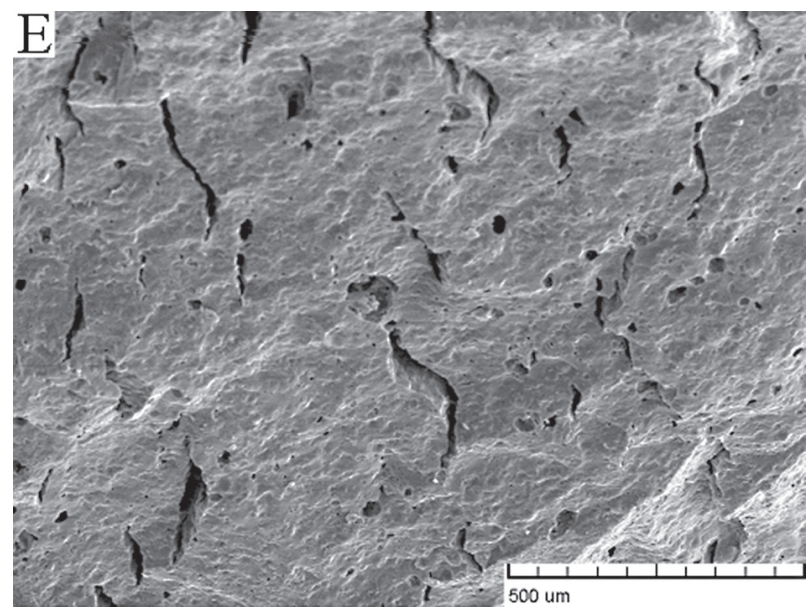

a)

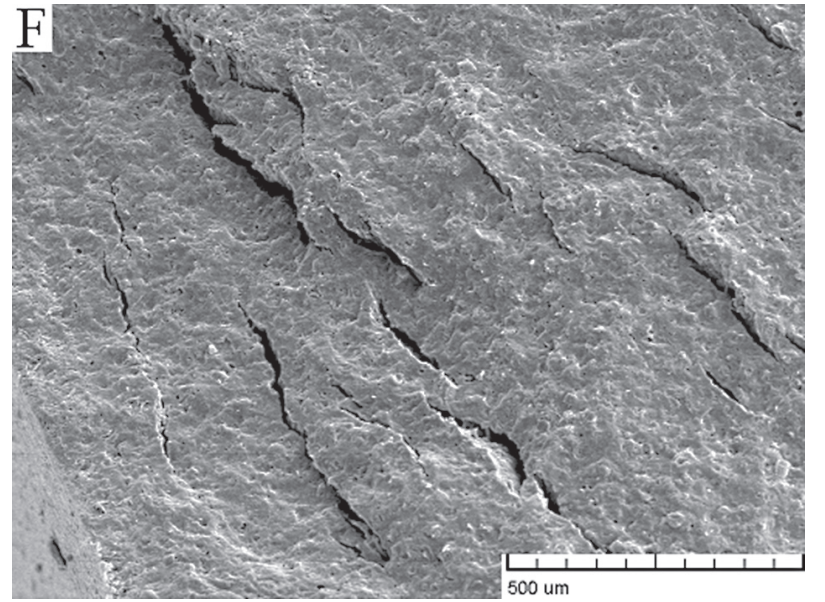

b)

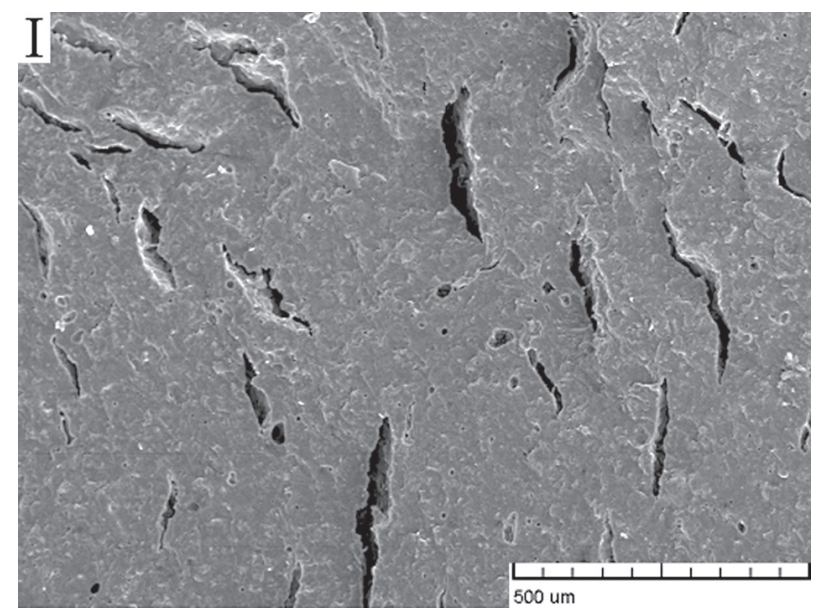

c)

Figure 9. SEM micrographs of samples: a) E, b) F and c) I. reliability is directly related to crack distribution in the ceramic structures. The material particles are rearranged by plastic flow due to lubricating effect of talc, producing relatively uniform microstructure. The rearrangement of particles occurs steadily until the talc content reaches the maximum value, $5.00 \mathrm{wt}$. \%. The lubricating effect becomes less marked when talc content is considered to be less than $2.50 \mathrm{wt}$ \%. Thus, greater talc content can facilitate plastic flow during the extrusion as a result, the Weibull modulus increases, considerably.

However, some porous materials like sample G may be failed due to surface or volume flaws. Each individual flaw population has typical size and lead to different distributions. As a result, the strength distribution resulting from different flaw populations will overlap and it cannot be supported by an individual distribution. In the case the failure probability can be defined by both of normal and Weibull distributions.

\section{CONCLUSIONS}

In the current investigation it was demonstrated that the microstructural differences between the ceramic beds, result in different behaviors in terms of compressive strength and reliability. The procedure has been proposed to ascertain a more suitable failure probability. The effect of microstructure defect on deviation from the normal distribution was discussed in detail by the experimental strength data. There is sufficient evidence that the Weibull distribution is frequently preferable respect to normal function in the adjustment of strength data. The findings of the present study based on Akaike information criterion and the Anderson-Darling test also indicate the Weibull distribution can provide an appropriate fits for fully vitrified rings respect to porous beds. The nepheline syenite-rich beds were more susceptible to crack propagation whilst the talc-based rings show the highest Weibull modulus and have the least susceptibility to fracture. This is of great importance because the microstructure of ceramic materials can be modified to increase their lifetime. Though, the use of Weibull distribution for the analysis of strength data can be reliable method in the design of random beds by modern technology, further processing factors such as material preparation, forming and sintering conditions should be considered to apply the results in commercial stage. Therefore, the study remains open from the mentioned view points.

\section{REFERENCES}

1. Salem A., Akbari Sene A. (2012). Optimization of zeolitebased adsorbent composition for fabricating reliable Raschig ring shaped by extrusion using Weibull statistical theory. Microporous and Mesoporous Materials, 163, 65-75. doi:10.1016/j.micromeso.2012.06.026 
2. Salem A., Afshin H., Behsaz H. (2012): Removal of lead by using Raschig rings manufactured with mixture of cement kiln dust, zeolite and bentonite. Journal of hazardous materials, 223, 13-23. doi:10.1016/j.jhazmat.2012.01.002

3. Salem A., Akbari Sene A. (2011): Removal of lead from solution by combination of natural zeolite-kaolin-bentonite as a new low-cost adsorbent. Chemical Engineering Journal, 174(2), 619-628. doi:10.1016/j.cej.2011.09.075

4. Treybal R.E. (1990). Mass Transfer Operation. $3^{\text {rd }}$ ed. McGraw-Hill Publishing Inc, Tokyo.

5. McCabe W.L., Smith J.C., Harriott P. (2001). Unit Operation of Chemical Engineering. $6^{\text {th }}$ ed. McGrow-Hill Publishing Inc, New York.

6. Strigle R.F. Jr. (1987). Random Packings and Packed Towers. Gulf Publishing Co, Houston Texas.

7. Salehi M., Salem A. (2009): Influence of sintering temperature on microstructural changes of ceramic Raschig ring. Korean Journal of Chemical Engineering, 26(2), 500505. doi:10.1007/s11814-009-0085-y

8. Villora J.M., Callejas P., Barba M.F., Baudın, C. (2004): Statistical analysis of the fracture behaviour of porous ceramic Raschig rings. Journal of the European Ceramic Society, 24(3), 589-594. doi:10.1016/S0955-2219(03) 00245-0

9. Salehi M., Salem A. (2010). Porosity-Strength Correlations in Ceramic Raschig Ring: Effects of Sintering Temperature and Water Content. International Journal of Applied Ceramic Technology, 7(6), 918-924. doi:10.1111/j.17447402.2009.02383.x

10. Wachtman Jr. J.B. (1996). Mechanical Properties of Ceramics. John Wiley and Sons, New York.

11. Quinn G.D., Morrell R. (1991): Design data for engineering ceramics: a review of the flexure test. Journal of the American Ceramic Society, 74(9), 2037-2066. doi: 10.1111/ j.1151-2916.1991.tb08259.x

12. Beygi Khosrowshahi Y., Salem A. (2010): A view on organic binder effects on technical properties of ceramic Raschig rings Bol. Soc. Esp. Cerám. Vidr, 49(5), 335-342.

13. Rostami N., Salem A., Paknjhad A. (2011): Influence of nepheline syenite on mechanical reliability of ceramic Raschig rings. International Journal of Applied Ceramic Technology, 8(2), 446-454. doi: 10.1111/j.17447402.2009.02435.x

14. Salem A., Rostami, N. (2013): Effect of nepheline syenite particle size on diametrical compression strength and reliability of extruded ceramic Raschig rings used in packed towers. Bol. Soc. Esp. Cerám. Vidr, 52(2), 79-87.
15. Salem A., Aghahosseini S. (2012): Determination of fluxing agents mixing ratio for enhancing thermal shock resistance of ceramic Raschig ring via a systematic approach. Thermochimica Acta, 545, 57-66. doi:10.1016/j. tca.2012.06.028

16. Salem A., Shirchi S. (2011): Reinforcing of extruded ceramic Raschig rings by dispersive particles: the effects of alumina and zirconium silicate on the reliability of a ceramic body. Journal of Ceramic Processing Research, 12(6), 615-623.

17. Carty W.M., Senapati U. (1998): Porcelain—raw materials, processing, phase evolution, and mechanical behavior. Journal of the American Ceramic Society, 81(1), 3-20. doi: 10.1111/j.1151-2916.1998.tb02290.x

18. Lee W.E., Iqbal Y. (2001): Influence of mixing on mullite formation in porcelain. Journal of the European Ceramic Society, 21(14), 2583-2586. doi:10.1016/S0955-2219(01) 00274-6

19. St John R.C. (1984): Experiments with mixtures, ill-conditioning, and ridge regression. Journal of Quality Techno$\log y, 16(2), 81$.

20. UNI EN ISO 10545-3.: Determination of Water Absorption, Apparent Porosity, Apparent Relative Density and Bulk Density, International Organization for Standardization, Geneva, Switzerland, 2000.

21. ASTM Standard C329-88.: Standard Test Method for Specific Gravity of Fired Ceramic Whiteware Materials. Annual Book of ASTM Standards, West Conshohocken, PA, 1988.

22. Doremus R.H. (1983): Fracture statistics: A comparison of the normal, Weibull, and Type I extreme value distributions. Journal of applied physics, 54(1), 193-198. doi: $10.1063 / 1.331731$

23. ASTM C1239.: Standard Practice for Reporting Uniaxial Strength Data Estimating Weibull Distribution Parameters for Advance Ceramics. Annual Book of ASTM Standards, West Conshohocken, PA, 2001.

24. Akaike H. (1974): A new look at the statistical model identification. Automatic Control, IEEE Transactions on, 19(6), 716-723. doi: 10.1109/TAC.1974.1100705

25. Stephens M.A. (1974): EDF statistics for goodness of fit and some comparisons. Journal of the American statistical Association, 69(347), 730-737. doi: 10.1080/01621459. 1974.10480196

26. Reed J.S. (1995). Introduction to Principles of Ceramic Processing, $2^{\text {nd }}$ ed. John Wiley and Sons, New York. 